\title{
Beyond one-dimensional representation: Challenges for Neighbourhood Planning in socially diverse urban settlements in Kisumu, Kenya.
}

\section{Authors}

First Author (and corresponding author): Julian Walker, Lecturer and Course Director (MSc Social Development Practice). The Bartlett Development Planning Unit, University College London, 34 Tavistock Square, London WC1H 9EZ, UK

t: + 44 (0)203 1085411 e:julian.walker@ucl.ac.uk | www.bartlett.ucl.ac.uk/dpu

Second Author: Stephanie Love Butcher, Doctoral candidate. The Bartlett Development Planning Unit, University College London, 34 Tavistock Square, London WC1H 9EZ, UK

t: + 44 (0) 7864919773 e: stephanie.butcher@ucl.ac.uk

\begin{abstract}
Neighbourhood planning bodies have become an increasingly important vehicle for residents in informal settlements in the Global South to pursue their interests, and make claims from city authorities. This paper explores the contribution that the structured representation of subaltern groups in Neighbourhood Planning Associations (NPAs) has made to the inclusiveness of neighbourhood planning initiatives in Kisumu, Kenya. At the same time, we explore the limitations of the emphasis on numerical representation of different social categories in NPAs, including: the ways in which the definition of social categories can reinforce existing power relations; the need to analyse and understand the relationship between planning claims and wider social and city-scale inequalities, and; the danger of concealing identity based conflicts of interests, and inequalities, when engaged in consensus building planning methodologies. Building on this analysis we present some principles for a 'diversity planning' approach to neighbourhood level planning.
\end{abstract}

Keywords: Neighbourhood Planning, Gender; Kenya, Diversity

Wordcount: 8390 
For residents of informal urban settlements in the Global South, who face material deprivations related to basic urban services such as water, sanitation, or housing, neighbourhood-level planning has become an increasingly important arena for change. At one level, it is anticipated that the participation of informal settlement residents in neighbourhood governance structures will better address tangible priorities and needs. On another, it is hoped that generating spaces for increased decision-making authority will challenge relational inequalities which represent broader exclusions of citizenship (Mitlin, 2001), both within informal settlements, and vis-à-vis the wider city.

However, this emerging democratic practice is not without challenges. Neighbourhood structures must balance the diverse planning priorities expressed by a wide array of urban dwellers, reflecting differences of gender, age or class, ethnicity or religion, levels of (dis)ability and education, or extended households and single parents, as well as contend with varying abilities of residents to exercise decision-making authority at the local level. Thus, while recognising their potential, critics have queried neighbourhood planning structures both in terms of their internal representativeness, and their external efficacy in influencing change (Butcher and Frediani, 2014; Cooke and Kothari, 2001; Dagnino, 2007, Rigon, 2014).

In this context, various strategies have been devised to ensure that diverse residents have an equal voice to drive policy and planning interventions in community-level political structures. Most commonly, these strategies rely on a 'politics of presence' (Phillips, 1994), which seeks to promote the numerical representation of subaltern identities. While this approach has been employed in a variety of contexts, from parliamentary quotas to NGO-led interventions, there are questions about the extent to which a quantitative approach to representation can address underlying and structural relationships of inequality. In other words, bringing diverse voices 
'to the table' does not always mean that conflicting planning needs linked to identity are revealed or addressed.

This paper will examine both the importance, and the limitations, of efforts to promote the politics of presence through neighbourhood planning in urban informal settlements. It does so by examining informal settlement Residents' Associations, which are increasingly prevalent in urban areas throughout Kenya. Such structures, bolstered by NGO inputs and supported in Kenyan public policy, have had significant successes in addressing particular urban planning priorities in informal settlements. Nevertheless, these associations also exhibit limitations in their reliance on a politics of presence, revealing tensions around processes of categorisation, the difference between presence and voice, and the methodologies structuring participatory planning processes. Reflecting on these lessons, this paper proposes some principles to guide a 'diversity planning' approach, seeking to build upon debates around representation and power, and exploring how they can be grounded in practice.

\section{Politics of Presence}

A critical battle for advocates of groups who are, or have historically been, denied equal citizenship rights, such as women or marginalised racial and ethnic groups, has been to demonstrate the importance of their direct representation in political decision making processes and structures. This builds on the assertion that democracy cannot be realised without the (direct) representation of the full range of social groups in a given context, on the basis that 'where policy initiatives are worked out for rather than with a politically excluded constituency, they rarely engage all the relevant concerns' (Phillips, 1994: 85). 
Attempts to ensure the political presence of subaltern groups have been pursued through a range of strategies. These have included quotas for women or other 'minorities' in legislative bodies, capacity building and financial support for candidates from under-represented groups, efforts to change attitudes amongst the electorate, or strategies to work on the political sphere from the outside via interest-based civil society constituencies. Simultaneously, 'community participation' interventions in development policy and planning have also often adopted a politics of presence, seeking to increase the decision-making opportunities for excluded groups at the neighbourhood or local government scale (Chambers, 1997; Hickey \& Mohan, 2004).

The importance of this approach has been substantiated by research demonstrating that when previously excluded groups gain seats in representative political structures, there are resulting changes in the kinds of issue that get on to the political agenda, as well as in the nature of political practice (Barry, Honour \& Palnitkar, 2004). Where linked with an empowerment agenda, the presence of subaltern groups in political forums is also understood to hold important impacts outside the political sphere, influencing their wider social status (Fraser, 2003; Phillips, 1997).

In this vein, community level political structures in informal settlements have been championed for their potential as spaces for subaltern groups to promote their interests and aspirations in governance and planning processes. Such institutions are imagined to better respond to the particular challenges faced by the urban poor, which often remain overlooked or marginalised in dominant urban development (Abers, 2003; Gaventa, 2004). However, while these structures hold potential to deepen democracy for residents of informal settlements, their efficacy faces a double set of barriers, both in terms of the internal representativeness of settlement-level political structures, as well as the extent to which these 
structures are recognised by, and able to meaningfully contribute to city level governance processes (Von Lieres \& Piper, 2014).

\section{Neighbourhood planning in Kenyan informal settlements}

The recent focus on decentralisation in Kenyan public policy has resulted in the increasing importance of the ward level in urban areas as a political space. A significant incentive for the creation of community-led ward level structures derived from the Local Government Act of 2001, which mooted neighbourhood associations as structures for receiving and allocating government funds through the LATF (Local Authority Transfer Fund). Following Constitutional changes in 2010, Kenya has experienced a radical change in city level government, with a shift to the new County-level government. This has had a significant impact on relationships between wards and the state, which remain in a period of transition. The progressive move to a new County government since 2011 has seen the Local Government Act replaced with the Urban Areas and Cities Act (2011), which has similarly provided a legislative framework for participation by residents in the governance of urban areas and cities.

In this context there has been a widespread move by actors in urban communities in Kenya, particularly in informal settlements, to solidify institutional structures for neighbourhood (ward) level planning, which can act as a vehicle to make claims from local government, development agencies and NGOs. These structures operate under a variety of titles, including Residents' Associations, Residents Committees, or Neighbourhood Planning Associations, and they have frequently been established with the assistance of NGOs. They are distinct from other urban community level structures in that, unlike many donor project created committees (such as water users associations or health councils), they are intended as durable community level structures which work beyond the frame of a single project. Furthermore, 
unlike other organisations of the urban poor, such as Slum Dwellers Federation bodies (including Muungano Wa Wanavijiji in Kenya), which make claims and advocate from outside government structures, neighbourhood associations aim to operate in tandem with local government (Cage, 2014).

Focusing on such neighbourhood planning structures, this paper is based on research conducted with a group of NPAs in the city of Kisumu, which were supported through the PPP Project $\left(2008\right.$ - 2013) ${ }^{1}$, delivered by the INGO Practical Action in partnership with two Kenyan NGOs: the Kisumu Urban Apostolates Programme (KUAP) and Shelter Forum Election, and funded by Comic Relief. The aim of the project was to improve the well-being, productivity and living conditions of residents in informal settlements, focusing in particular on the Kenyan settlements of Kisumu and Kitale, but with a view to developing approaches and models that could be replicated more widely in urban informal settlements throughout Kenya and East Africa.

The data on which this paper is based is drawn from a series of research engagements based around the PPP project, including both academic research ${ }^{2}$ and applied research ${ }^{3}$. The methodology was qualitative, and included review of secondary data and unpublished project documents produced by the three NGOs managing the PPP project, as well as collection of primary data. Primary data collection was conducted through interviews and participatory research exercises (including participatory photography) with residents of the informal settlements targeted by the project and one informal settlement not targeted by the project. Research was undertaken with residents both as individuals, and in collective associations (e.g. Neighbourhood Planning Associations, Social Audit teams, Community Based

\footnotetext{
${ }^{1}$ People's Plans into Practice: Building Productive and Liveable Settlements with Slum Dwellers in Kisumu and Kitale.

${ }^{2}$ This includes a Masters of Research dissertation undertaken as part of a doctoral programme by one of the authors, as well as supervised fieldwork projects undertaken by staff and Masters students studying for the MSc in Social Development Practice at University College London in 2013, 2014 and 2015.

3 Field research undertaken by one of the authors for the Final Evaluation of the PPP project in 2013.
} 
Organisations, Women's Groups, Youth Groups, Housing Cooperatives, and Waste Pickers Cooperatives). Interviews were also conducted with a range of secondary stakeholders including government officials and elected representatives from the Unit, Ward, County and National level, and staff of NGOs and international organisations working in Kisumu. Findings of the research were presented to research participants and discussed during public workshops held at the KUAP Pandipieri centre in Kisumu in 2013, 2014 and 2015.

One of the core objectives of the PPP was that 'poor people in informal settlements have more say in decisions that affect them'. This was pursued through capacity building measures to either establish new, or build already existing, NPAs. The approach of the PPP clearly espoused the ideals of the politics of presence, promoting explicit methods and requirements to ensure different categories of residents were represented in NPA structures and activities. In particular, one of the main criteria guiding residents' election of NPA Executive Committees was that they must include: both men and women, a landlord, a tenant, a community health worker, and a youth representative in their membership.

These measures to ensure the presence of defined subaltern groups (in this case, women, youth, tenants) were further built on throughout the process of forming and working with the NPAs (see figure 1). This included, for example, less formal efforts to foster inclusion (e.g. of people with disabilities) in the community mobilisation process. More explicitly, the project later saw the creation of further decentralised (sub-ward level) committees, to confront the potential of 'elite capture' highlighted during the project's mid-term evaluation (MTE) by further decentralising committee activities. NPA activities also included participatory planning events aimed at the production of SWAPs (Strategic Ward Action Plans), in which women's and youths' CBOs were explicitly targeted (and in fact made up the majority of attending organisations). When the different planning priorities identified in each ward's SWAP were put into practice, there was a similar emphasis on mixed representation within 
the responsible 'task forces' established. Finally, where employment opportunities were created (such as managing water kiosks, employment in new solid waste enterprises and sanitation blocs, and membership of urban agriculture cooperatives), this targeted the inclusion of what the project had defined as 'vulnerable' groups in Kisumu; specifically, people with disabilities, youth, and people living with HIV/AIDS.

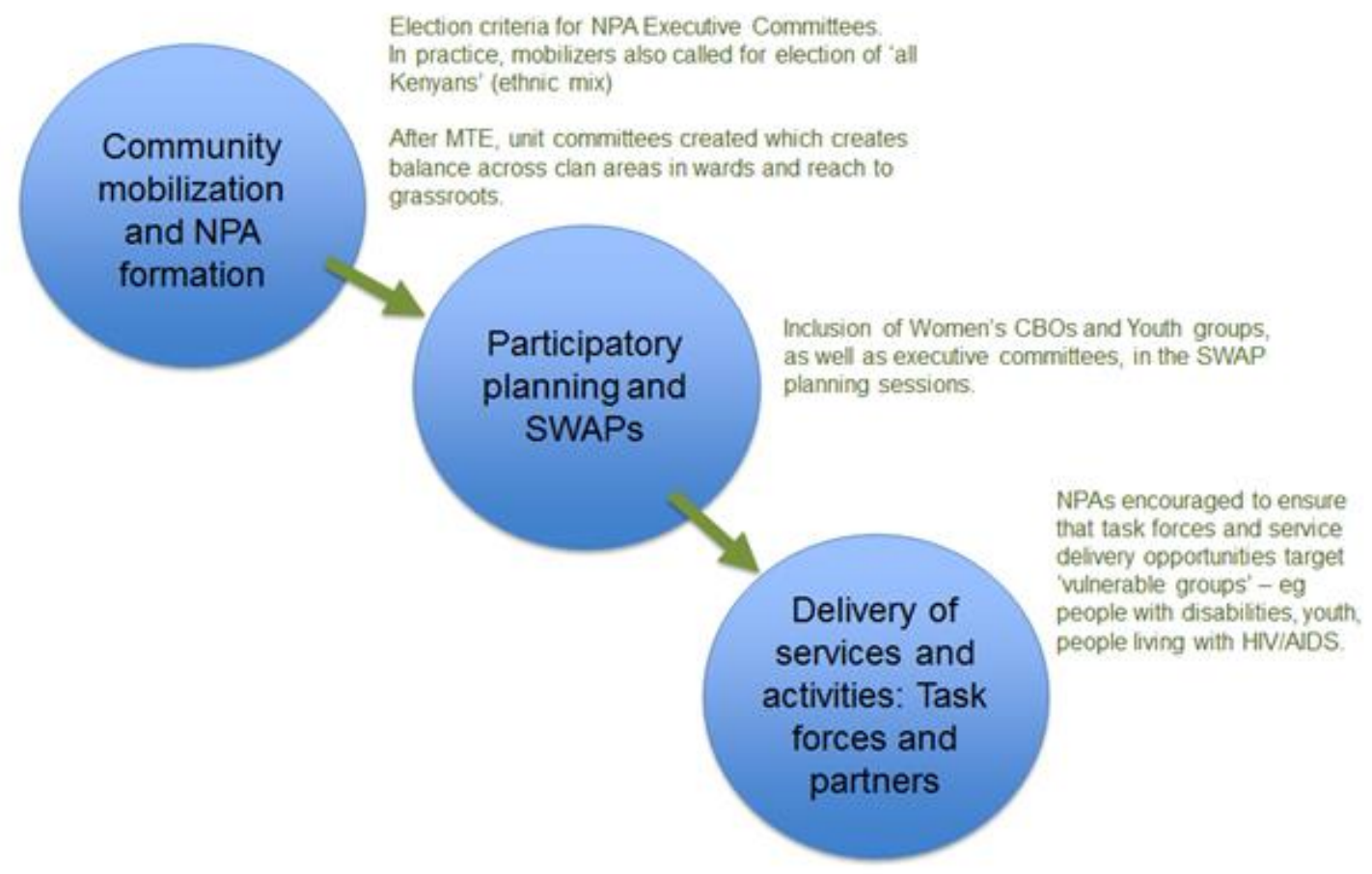

Figure 1: Neighbourhood Planning Association development process

It is worth noting that this approach reflects a wider trend occurring in Kenya, particularly where the creation of Residents' Associations is supported by NGOs. In Kisumu for example, while the PPP worked with NPAs in four informal settlement wards (Manyatta A, and B, and Nyalenda A, and B. see figure 2) the project only established three NPAs. The NPA of Manyatta A had previously been established with the support of another Kenyan NGO, guided by similar rules about the representation of women, youth and tenants on the committee. Likewise, other informal settlements in Kisumu outside the scope of the PPP project (Obunga and Kibos) also have NPA-type structures, demonstrating similar efforts to 
ensure mixed representation on the body's leadership committees. Thus, while it appears that the PPP approach has gone further in promoting inclusion in (SWAP) planning processes and the delivery of projects by the NPAs, the general principle of safeguarding mixed representation on NPA committees is fairly well institutionalised in Kisumu.

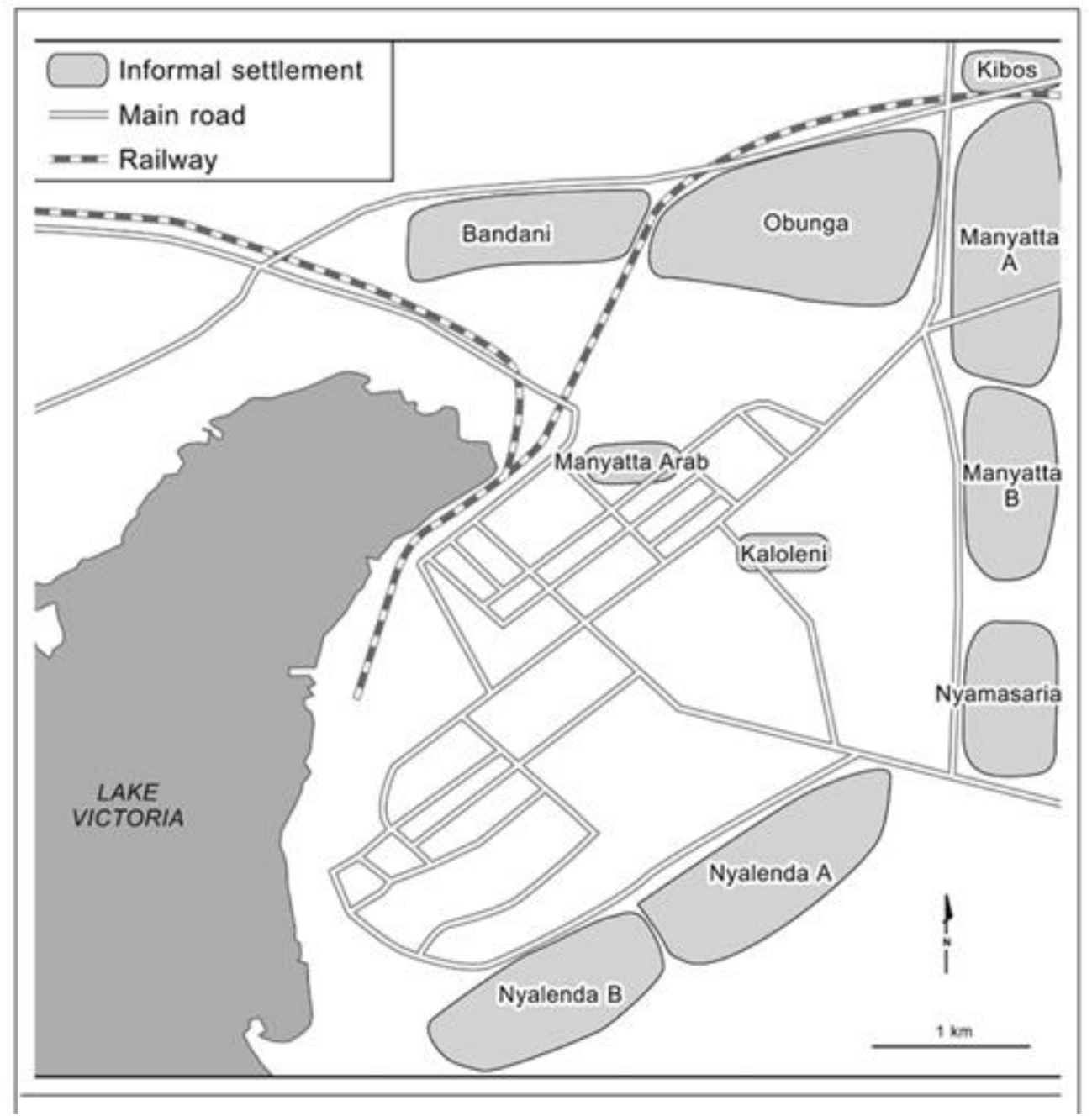

Figure 2: Main informal settlements in Kisumu (Karanja, 2010)

This approach is not limited to Kisumu. Research on ward-level Residents' Associations in informal settlements in Nairobi documents similar rules about diverse membership quotas on leadership committees (Rigon, 2014). This approach is also reflected in the UN-HABITATled Kenya Slum Upgrading Programme (KENSUP), which established similar mechanisms for the community election of a Settlement Executive Committee (SEC) to manage their 
upgrading programme. Indeed, this approach can be traced back as far as the Small Towns Development Project (STDP), an informal settlements upgrading programme initiated in 1992 by the Ministry of Local Government and German Technical Cooperation (STDP, No date).

\section{Outcomes of inclusive NPAs}

Efforts to ensure that NPAs promote the formal representation of groups such as women, youth, and tenants have made important contributions to these groups' interests. The final PPP final programme evaluation highlighted several positive outcomes of these efforts, particularly in relation to increased livelihoods opportunities, such as water kiosks and smallscale waste enterprises, as well as in terms of wider-reaching participation in local political structures. This has benefited a wide spectrum of the population in a context where particular groups have all been excluded in different ways from local level politics (Muna, Stanton \& Mwau, 2014).

In addition, residents highlighted a range of impacts extending beyond the identified scope of the project, citing the increased sense of security, dignity, or confidence as a result of the SWAP process and its subsequent outcomes. For instance, in addition to the planned impact of engaging waste pickers in a social enterprise model (to both build their livelihoods, and provide solid waste collection services in project wards), solid waste managers and employees also reported a sense of greater legitimacy and standing than previously experienced within their traditionally devalued profession.

This practice of safeguarding spaces of participation for certain identities has also contributed to raising the visibility of particular concerns, and helped generate cross-cutting solidarities across settlements. For instance, work with the Practical Action-supported NPAs revealed the

high importance of issues of disability for NPA members. This was manifested both in a 
concerted effort to create employment opportunities for disabled residents in community water kiosks, and in the prominence given to issues of accessibility in discussions at NPA meetings. Similarly, the different impacts for structure owners and tenants was a major topic of debate in the face of evictions along the major Nyalenda Ring Road resulting from a major upgrading initiative in the city. In both cases NPA members highlighted the role of these representational structures in stimulating reflections on the differentiated planning needs and aspirations of various identities within the settlement.

This strategy also acted as an entry point for networking, to scale up and present a challenge to city-wide structural barriers to inclusion. This was most clearly evidenced by the success of the Kisumu Waste Management network (KIWAMA) which works directly with the NPAs and which has been instrumental in confronting the persistent stigma attached to waste pickers in Kisumu. In May 2014 the network achieved an important legal victory (Erick Okeyo v County Government of Kisumu \& 2 others, High Court of Kenya at Kisumu Petition Number 1 'A' of 2014) in opposing the proposed tendering of the city's waste collection to a private international large-scale corporation, which would have significantly impeded the viability of small-scale entrepreneurs operating in Kisumu's informal settlements. In this case, capacity-building measures implemented through the PPP, as well as the establishment of institutionalised spaces of political representation for Kisumu's waste pickers, was identified by KIWAMA leaders as supporting them to highlight and oppose a city-wide and structural set of unequal relations.

\section{The limits of 'inclusive' planning structures}

While the focus on mixed representation in Kisumu's NPAs has demonstrated significant gains, a close examination of the PPP project also suggests that this tactic is a crucial but by no means sufficient measure to ensure socially just and inclusive policy outcomes. With 
specific reference to neighbourhood planning, the need to move beyond numerical balance is crucial for three overarching reasons, which we will explore in more detail below. Firstly, defining 'categories' for representation can generate problematic outcomes; secondly, the presence of subaltern groups in planning structures does not necessarily translate into their greater voice in decision-making; and thirdly, regardless of who participates, the planning process and methodologies adopted will also critically determine which interests planning outcomes are likely to reflect. While the case of Kisumu will be used to demonstrate these tensions, it is intended to stimulate wider reflections for organisations working to support informal settlement residents in a range of contexts.

\section{Defining categories for representation}

Ensuring the presence of key social groups in political structures requires identifying, and agreeing upon, the categories of women, men, girls and boys who should be represented. This raises a number of questions about how structures such as NPAs define and promote categories for involvement in their activities. If categorisation is undertaken without reflection, this can present the risk of consolidating, rather than confronting, existing power relations and inequalities.

Firstly, deciding whose inclusion should be safeguarded in spaces of participation necessarily also implies deciding which identities should not be targeted for inclusion. In the case of the PPP, emphasis was placed on groups who are likely to have distinct interests with reference to neighbourhood planning (i.e. structure owners vs tenants), valuable expertise (i.e. community health workers), or groups who are known to be marginalised from political decision-making (i.e. women and youth). However there are other key identities in Kenya, linked to distinct planning needs, as well as to stigma and exclusion from decision-making, which were not included. For example, people living with HIV/AIDS were notable as an 
absent target group, particularly given that Kisumu has the $3^{\text {rd }}$ highest prevalence of Kenya's 47 counties $^{4}$, and that HIV status is linked to specific infrastructure and planning priorities, as well as barriers to representation. Similarly, the lack of focus on balanced ethnic representation was also striking given the importance of ethnicity for social conflicts and inequalities in Kisumu, though, as will be later discussed, there was a strategic logic for this omission.

Moreover, once categories have been identified, the way in which these categories are constructed can also have implications on the recognition and space for agency of members of the defined social group. A literature on labelling in development (Moncrieffe \& Eyben, 2007) highlights that the construction of social categories in itself can create, reinforce, or challenge power dynamics with outcomes that can be both positive and negative, or even both at once. For example, the frequent identification of women, youth or people with disabilities in policy as 'vulnerable groups' in policy documents can have problematic outcomes, serving to reinforce stigma attached to these identities, with impacts on their agency and voice. At an extreme, this may even be a means of justifying policy approaches which serve to reinforce discrimination. This has been illustrated, for example, by the policy treatement of gypsies as a vulnerable group in Italy (Sigona, 2005). While it is politically important to highlight inequalities faced by groups that can increase their vulnerability, there is a critical difference between such vulnerability being claimed or self-defined by 'vulnerable groups', and vulnerability being demarcated by wider society or development agencies.

Beyond the minefield of defining categories for representation, a further issue is that people rarely neatly represent 'their' categories as interest-based constituencies. Even where

\footnotetext{
${ }^{4}$ According to government research into the number of clients attending ante natal-clinic who test positive for HIV AIDS (16.2\% in Kisumu county, compared to national average of 5.9\%). Kisumu follows only its two neighbouring counties of Siaya and Homa Bay in this dataset (Commission on Revenue Allocation, 2011)
} 
representatives are selected by their own assumed identity constituency (of women, youth, etc) there is not necessarily a clear set of women's or youth's interests for them to represent. The nature of social identity means that we do not have what Sen (2006) has termed a 'singular affiliation', meaning that as individuals we hold a range of different identity based interests. These can often place our interests in conflict with those of other people in a category (e.g. gender, ethnicity, age group) that we are part of. In her seminal work on race and gender, Crenshawe explores this issue through the concept of intersectionality, which 'highlights the fact that women of colour are situated within at least two subordinated groups that frequently pursue competing political agendas' (Crenshawe, 1993: 1251-1252). Ergo, women of colour are unlikley to have their political interests fully or accurately represented by white women, or by black men.

Such political interesectionality means that the interests of those with multiple subordinated identities are likely to have political interests that remain invisible (Purdie-Vaughns \& Eibach, 2008). In these cases, dominant interests may continue to be served through the inclusion of representatives of subordinate interests (e.g. women), who are at the same time members of another dominant group (e.g. higher income class or dominant ethnic group). In the context of neighbourhood planning in Kenya, Rigon (2014) has documented how such a situation can arise in his work on Residents' Commitees in an informal settlement in Nairobi. Here, quotas of women and youth on Residents' Committees were filled largely by women and youth from structure owning (landlord) households, who appeared in practice to promote the interests of structure owners, more than those of women and youth.

It is also important to note that people are more than their categories. Thus, seeing people only in terms of their demarcated categories can create a situation in which (subaltern) groups end up only being expected, or even allowed, to talk about issues related to the categories that they are expected to represent. In Kisumu, for example, it was not uncommon to witness 
youth speaking only about issues related to youth unemployment, for instance, while the wider range of issues related to nighbourhood planning remained the domain of those without a specified category to represent (i.e. those who are not members of 'vulnerable' or 'minority' groups). Furthermore, while it is critical for representatives of subaltern groups to be present in political forums, this should not eclipse the importance of solidarity between identities, and empathy for the burden of inequalities from people who do not face such inequalities. This has been highlighted by, for example, the recognition of the importance of men as allies in feminist struggles for gender justice (Levy, 2000; Sweetman, 2001).

In conclusion, the definition of categories for the representation of subaltern groups can become problematic where it leads to subaltern interests being perversely obscured and/ or agency being limited or denied. Nonetheless, the 'politics of presence' remains a vital component of democracy and social justice, and this clearly requires some form of categorisation of social groups so that balanced representation can be assessed and strategies for remediation can be pursued. The question therefore is not how to avoid using such categories, but rather how to construct and use them in reflexive ways which guard against some of the pitfalls discussed above.

\section{The gap between presence and voice}

In terms of the second limitation of a focus on presence, there is an extensive literature on power relations in participatory spaces which emphasises that physical presence is not enough to ensure voice or influence policy outcomes (Cornwall, 2002, 2004; Cooke and Kothari, 2001; Mayoux, 1995). This may be the case where subaltern groups lack the confidence or capacity to actively participate in such arenas, or where persistent societal expectations continue to limit or circumscribe participation of certain groups even when they are invited to the table. 
This is more than evident in Kenyan informal settlements. For instance, Karanja, discussing the NGO Pamoja Trust's experience of enumeration in informal settlements in Kenya, highlights that local micro-politics often mean that the needs and priorities of groups such as female-headed households, immigrants or tenants, may be rendered invisible in wider community discussions and activities (2010). Similarly, Cage's research into civil society organisations in informal settlements in Kisumu reveals that women are often keenly aware of gendered power relations. As a result, many female residents indicated that they frequently preferred to join women's organisations rather than mixed community organisations, on the basis that: 'In African culture men want to lead. It is harder to convince them, and to get to know each other. If there are men they want to get their decisions heard.' (Women's group member.) (Cage 2014: 15). In the case of NPAs in Kisumu, such identity-based power relations are often visible in the workings of NPAs; for example, women's voices being confined to traditional 'women's issues' such as health (for example, during a recent polio vaccination campaign).

\section{Planning methodologies}

The third reason for the need to move beyond a focus on the 'presence' of interest groups is that if the planning methodology is blind to social relations, then issues of social identity are unlikely to be explored in any depth and/ or be reflected in planning outcomes, regardless of who is involved in planning discussions. What is therefore critical is moving beyond a focus on who is present in planning forums, to also considering how the content of planning discussions and methodologies ensures (or sidesteps) a focus on and analysis of identitybased needs and inequalities.

As previously discussed, in the case of the NPAs supported by the PPP there was a strong focus on ensuring the presence of various social groups in the planning process. This was 
encouraged through measures such as the makeup of the elected NPAs, and the invitation of CBOs including a large number of women's and youth groups. However, there was less evidence of efforts to ensure that planning processes and methods included a discussion of diverse needs or aspirations in relation to settlement development. The baseline data collected for the production of SWAPs included, for example, household composition and population characteristics, but it is not clear that this was used to inform the analysis of planning priorities through the key analytical tool used, which was participatory problem tree analysis. In other words, this approach did not include methodological guidance on how to reflect on the underlying causes of community problems and the extent to which these were entangled with power relations built around social identity. In Kisumu, for example, this might be linked with norms around patriarchy, ethnic hierarchies, the privileging of elders, or class based value given to land and housing ownership. The result is an analysis of problems which does not factor in identity-based social roles or power relations, resulting in largely 'technical' responses to the priorities identified (see Figure 3). 


\section{Development challenges in Upper Unit}

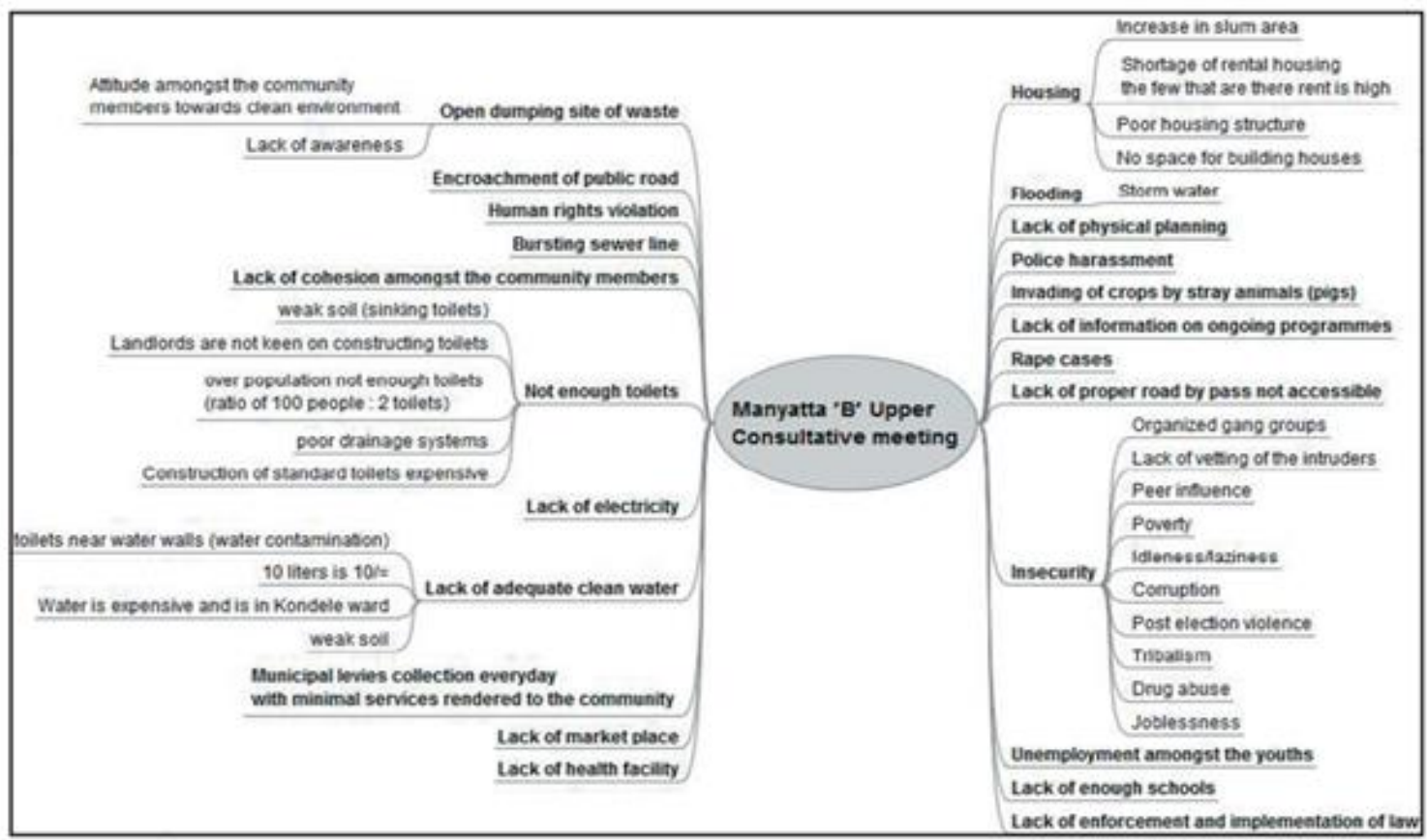

\section{Figure 3: PPP Problem tree analysis for Upper Unit, Manyatta B Ward.}

Source: Manyatta Strategic Ward Plan 2010 - 2014: Building Productive and Liveable Settlements with Slum Dwellers in Kisumu.

In Figure 3, for instance, the identified problem of a 'lack of adequate clean water' is attributed to apolitical issues including cross-contamination from poorly sited toilets, prohibitive expense, or weak soil. While these are all recognisable factors, this does not generate a discussion on some of the underlying structural barriers to adequate access to piped water that impact residents differently. For example, the Kenyan policy environment, as exemplified by the 2002 Water Act, favours the privatisation of basic urban services with an emphasis on cost-recovery and financial sustainability (even in 'pro-poor' models of service delivery). This has led to the prioritisation of investment in trunk infrastructure around the peripheries of settlements and adjacent to higher-income areas, further exacerbated by the increasing profit-oriented pressures of land-development in the city. 
Within the current emphasis on investment in areas of economic viability, residents located in poorer areas are unlikely to be served in the near future by municipal systems.

Nor does this analysis allow for conversation on how a particular approach to water provision, in this case, a policy focus on market mechanisms intended to ensure costrecovery, may intersect with social norms and practices built around different aspects of identity. For example, there is no methodological space to reflect on the gendered dimensions of water collection and usage, which in Kisumu is still overwhelmingly the responsibility of females in the household. This generates particular planning needs for women and girls related to access to and control of clean water, as well as ramifications in terms of how clean water is allocated between reproductive and productive uses (Moser, 1993). Interviews conducted with female residents indicated that powerful societal expectations related to women's responsibilities often limited their participation to approved functions related to 'household management', which did not always translate to greater authority in the public sphere.

In addition to the ways in which planning methods treat identity issues, another methodological challenge is the problematic focus of decision-making forums such as the NPAs on reaching consensus. There is clearly a need to reach key decisions so that the outcomes of community forums can lead to a platform for action and positive change, such as the SWAPs produced by NPAs. However, while the generation of consensus can be key in legitimising and producing such outputs, it is also important to ensure that this does not occur at the expense of silencing diverse opinions. As Mouffe has noted, 'too much emphasis on consensus, together with an aversion towards confrontation, produces both apathy as well as a lack of interest in political participation' (Mouffe, 2002:10). Moreover, an emphasis on consensus which exludes dissenting voices may mask conflict and lead to majority rule, thereby obscuring minority interests. Reframing the potential of participatory planning 
processes requires not only equitable representation, but also opening up discussions that reflect upon the interests of different identities vis a vis wider urban trends. Even if prioritisation processes must favour some interests over others, it is important to capture and document these trade-offs as the basis for future interventions, and to inform continued dialogue on the needs and aspirations of diverse groups.

\section{Diversity and planning}

Given these concerns, it is clear that while ensuring 'presence' in political formations such as NPAs makes an important contribution to bringing a diversity of voices to grassroots planning claims in informal settlements, there is still a need to move further to ensure a socially just neighbourhood planning process. But what does this mean, in practical terms, in relation to the problems discussed above? While the particular nature of the issues outlined above are rooted in the context of Kisumu, this case also provides ground for reflecting more generally on how these three identified tensions are emerge in planning in informal settlements more generally. The following section draws from existing debates which seek to address some of these stickier issues of representation, using this as a base from which to develop key principles to guide a 'diversity planning' approach.

\section{Defining social categories}

While defining categories to measure and promote diversity in political bodies remains necessary, the associated problems of labelling highlight the need to approach this with a critical reflection. There are some broad principles which may help to guide this reflection. Firstly, it is vital to analyse how the definition of 'categories for inclusion' colludes with, or unsettles, existing social hierarchies. Where it is found that the definition of categories for representation holds the potential to create (or exacerbate existing) conflicts or privilege 
certain groups, (Eyben, 2007) there are strategies which can seek to unsettle these power dynamics.

For example, Kisumu has experienced some of the country's worst inter-ethnic violence after the 2007 national elections, leaving significant tensions between Luos, Kikuyus and other ethnic groups. In this context, power dynamics and the construction of ethnicity were a serious concern, and the PPP project did not want to explicitly highlight ethnic representation in the NPAs. Nonetheless, as political interests are tightly bound with ethnicity in Kenya, this was not an area of balanced representation that the PPP could sidestep in the interest of avoiding conflict. Community mobilisers addressed this strategically by appealing to communities to elect 'All Kenyans' with an unspoken reference to ethnic identity, and through the subsequent monitoring of elected commitees to ensure that, indeed, a balance of ethnic groups were represented.

Secondly, reflecting on the way in which intersectionality obscures the relationship between representatives and their 'constituency', there is a need to move away from the essentialist idea that a member of a group necessarily speaks for that group. Phillips stresses the need for approaches to 'the gender composition of elected assemblies that detach the claim for parity of representation from essentialist definitions of 'women' or 'men'” (Phillips, 1997: 151). One way of approaching this disconnect is an appeal to 'transversal politics' as a part of which '...feminists and other community activists should not see themselves as representatives of their constituencies (unless they were democratically elected and are accountable for their actions). Rather they should see themselves as their advocates, working to promote their cause' (Yuval-Davis, 1999: 95). The kind of political formations required by transversal politics, therefore, rather than comprising distinct interest groups, with representatives who are able to advocate for these shared interests, requires the formation of epistemological communities built around shared values, which may encompass a diversity of 
specific interests. In other words, beyond safeguarding elected representation, participatory structures become valuable vehicles for the development of cross-cutting solidarities or raising the visibility of minority issues, and should be evaluated for their abilities to develop such conversations.

\section{From presence to voice}

The second challenge identified above is the need to ensure that presence is translated into voice. There is a huge literature on participatory development and power which aims to bridge this gap. This advocates making power relations, and the colonisation of participatory spaces by hegemonic power relations, visible (Cornwall, 2002), and moving beyond technocratic knowledge by using methods of communication that subvert existing hierarchies (Chambers, 1997; Hickey and Mohan, 2004; Mosse, 2001). However, there are also more specific issues in ensuring that those chosen as advocates of specified social groups are enable to enact voice in relation to their constituency. Rules for institutions such as NPAs may ensure the presence of group such as women or youth, but if these individuals are to successfully act as advocates for their identity based constituencies, this requires that they are informed and empowered to act in this role. There is a significant difference between a constellation of individual youths or women on the one hand, or, on the other, youths and women who are embedded in constituent organisations where issues relating to their identity based needs and aspirations have been debated and explored. The latter requires representatives to have collectively reflected on the interests and realities of the group that they are selected to represent (a fundamental pre-requisite for an 'epistemological community').

\section{Planning methodologies and identity issues}


Finally, in addition to ensuring that subaltern groups are represented and able to exert voice in neighbourhood planning bodies, another key point is the methodology of planning itself. Planning approaches which are designed to question the relationship between diverse social identities and planning do already exist, and gender plannning in particular has made an important contribution to this end. The Development Planning Unit (DPU) Gender Policy and Planning method, building from the work of Moser (1993), is one such approach which seeks to ensure that planning reflects the complex lived realities and aspirations of diverse groups of women and men, girls and boys. Such approaches have been critical in providing a framework which ensures that contested social realities and practices (often rendered invisible in more traditional, technocratic approaches to planning) are made legible. Thus, for example, gender planning methods have been critical in positing approaches which widen the scope of economic planning to include a focus on 'care' as an economic practice (Elson \& Cagatay, 2000), emphasising the importance of unequal, gendered, access to and use of time as a function of inequality and poverty (Chant, 2006), or exploring the gendered nature of how (urban) spaces mediate the 'deep distribution' of public goods such as transport (Levy, 2013).

Gender planning methodologies offer a valuable entry point from which to structure approaches which embrace the relationship between diverse social identities and planning needs. Nonetheless, ensuring that these principles are integrated into mainstream planning processes continues to be a struggle. Like any methodology which attempts to reveal and transform unequal power relations, gender planning has been subject to both marginalisation and co-optation (Mukhopadhyay, 2004). Gender planning does explicitly reject simplistic women/ men binaries, and methodologies such as that of the DPU Gender Policy and Planning Programme emphasise the intersecting nature of social identity. However, the history of gender planning as emergent from the women's movement means that some of its 
analytical approaches may be less suitable for understanding needs related to aspects of social identity other than gender. For instance, a core element of gender planning is a focus on the equal citizenship rights of women and their ability to enact autonomous agency, and developing means to address barriers that inhibit this. This emphasis on autonomy however, while important, may draw attention from other concerns which hold relevance for other social identities. Thus, White, for example, has demonstrated that an overemphasis on individual autonomy is problematic for discussions around child rights, which must also emphasise relationships of care with respect (White, 2002). This case can also be made for some forms of disability (Walker, Frediani, \& Trani, 2012). Gender planning, on the other hand, while having a stong emphasis on care, tends to approach it more in terms of responsibilities and time burdens (Walker, 2013). Furthermore an analysis of care as a right is increasingly ignored in growth oriented, neo-liberal analyses of citizenship, which see rights as devolving from economic participation (Dagnino, 2007). In this light a crucial element which could explicitly augment gender planning into a broader 'diversity' planning approach would be analysis of which groups and households have a need for care, or support (for example, those with specific disabilties, or child headed households), and where this support should come from (the state, the market, or social networks).

A second area in which planning methods could be broadened conceptually to take on a wider range of identity concerns is the analysis of discrimination and power. The ways in which patriarchy operates can be quite distinct from the forms of discrimination linked to other social identities. This is, in part, because while gender embodies a set of relationships that is present in everybody's lives, other social identities can be presented as purely 'other', or as 'outside society'. This may be the case, for instance, for sexual or ethnic minorities, who may be explicitly rejected, or invisibilised. As such, gender discrimination may tend 
towards what Cleaver has termed 'adverse inclusion' (Cleaver, 2005) while discrimination against, say, sexual minorities may be manifested more in terms of outright exclusion.

Finally, another issue previously dicussed in relation to planning is the problematic focus on reaching a consensus on planning outcomes. This is reinforced by concerns about the constraints on subaltern identities' voices in planning spaces. It is also a particular issue for groups who are a numerical minority in the relevant population (for example ethnic or religious minorities, people with specific disabilities) as a focus on consensus through majority voice is likely to mean that the interests or claims that they voice may disappear from the final agreed outcomes of planning. As highlighted by Mouffe (2002), much of the importance of democratic processes lies in the debate as in the outcomes, and an overemphasis on consensus may elide points of view which reflect alternative planning needs. This requires diversity sensitive planning methods to address how planning processes can avoid creating a false impression of consensus and masking conflicts.

While ultimately a plan needs to be developed in which decisions are made and agreed, it has previously been highlighted that 'dissensus' in planning and design can make a crucial contribution to justice planning outcomes (Frediani, 2012). An approach to planning which seeks to work through dissensus implies, at the very least, documenting and highlighting the different voices and interests expressed, and in particular those that have not been addressed in the final 'agreed' plans (which should inform future planning cylces). Beyond the outcomes of discussions, it also sets an important processual precedent, deepening democratic practice through revealing the multiple and alternative priorities connected to a range of identities.

\section{Conclusions}


The 'politics of presence' has informed a crucial set of interventions for residents living in Kisumu's urban informal settlements. Clear categories outlining the participation of residents such as tenants, women, youth, and people with disabilities have been key in raising the political visibility of these groups, with participants highlighting a sense of increased wellbeing as a result of their participation in NPA activities. This has been supported by inclusive mobilisation strategies undertaken explicitly (such as safeguarded participation in task forces at the sub-ward level), as well as implicitly (promoting ethnic balance without clear categorisation). These approaches have helped NPAs to build cross-cutting solidarities, and raised the visibility of issues affecting particular groups.

Nonetheless, there are still lessons that can be drawn from this case which highlight some of the limitations of a focus on 'presence'. Most evidently, there is some indication that groups such as women and youth were relegated to decision-making in areas coherent with the existing gender division of labour, for example, the association of women with householdlevel water consumption, or community health activities. While this increased the decisionmaking authority of subaltern groups in certain domains, in other cases it was less successful at addressing deeper systemic inequalities; for instance, in challenging the unequal division of productive and reproductive labour at the household level. Similarly, the NPA focus on the representation of different social groups has not been as effective in focusing analysis and debate on the ways in which wider urban development trends in the city have been affecting informal settlement residents differentially, generating different planning needs.

Thus an exploration of the Kisumu experience of neighbourhood planning indicates that the politics of presence, while a crucial first step, needs to go further if it is to build a diversity perspective into the planning approach itself. Building on gender planning methodologies, learning from the labelling literature, and seeking to engage issues of power in participatory spaces could help to inform this kind of diversity planning. This approach would necessitate a 
number of principles. First, it would involve embedding approaches to neighbourhood planning within a wider project of capacity building for marginalised groups which goes beyond formal spaces of planning, and enters into the fabric of everyday life. This might mean, for instance, interventions which confront exclusionary discourses and practices which reproduce identity-based inequalities at the community and household levels, such as those which structure norms related to reproductive and productive activities.

Second, a diversity perspective requires seeing planning not as a way to generate a coherent list of priorities for the neighbourhood, but rather in understanding how diverse identitybased needs generate different, and sometimes conflicting, spatial aspirations. In other words, it requires methodologies for exploring how different needs (related for instance, to recreation, economic productivity, or household management) may complement or contradict each other, and how planned interventions might cater to a particular set of people, needs, or priorities. Third, such an approach might not easily lend itself to a clear consensus on neighbourhood priorities, thereby requiring flexible planning approaches which are open to multiple outcomes. Crucially, such an approach would also require that compromises related to finalised plans and implemented actions be made visible in the documentation of the planning processes and outcomes.

Reflecting on these issues could help organizations committed to diversity and social justice, such as the NGOs which managed the PPP project, move interventions from a focus limited to the politics of presence, towards a deeper engagement with concerns of diversity in planning. This requires moving forward from the lively theoretical debates on the intersectional nature of social identity, and the complexity that this brings to an analysis of social change and democratic practice, to embedding these principles in practice. It also calls for further research on what this means for the methods of organizations engaging with neighbourhood planning in practice. In particular, future research would need to unpack how, 
or whether, diversity planning principles affect the durability of NPA and similar neighbourhood level structures by explicitly revealing diversity and dissensus. In doing so, there would be the scope to expand the potential of neighbourhood planning to contribute to more just spatial planning processes and outcomes for diverse sets of residents.

\section{References}

Commission on Revenue Allocation (2011). Kenya, County Factsheets: Government of Kenya.

Barry, J., Honour, T., \& Palnitkar, S. (2004). Social movement, action and change: The influence of women's movements on city government in Mumbai and London. Gender Work and Organization, 11(2), 143-162. doi: DOI 10.1111/j.14680432.2004.00226.x

Cage, C. (2014). Transforming the social capital of the urban poor: Lessons from Kisumu, Kenya. Development in Practice, 24(1), 3-17. doi: 10.1080/09614524.2014.867306

Chant, S. H. (2006). Re-visiting the 'feminisation of poverty' and the UNDP gender indices : what case for a gendered poverty index? London: Gender Institute.

Cleaver, F. (2005). The inequality of social capital and the reproduction of chronic poverty. World Development, 33(6), 893-906. doi: http://dx.doi.org/10.1016/j.worlddev.2004.09.015

Cornwall, A. (2002). Making Spaces, Changing Places: Situating Participation in Development (Vol. IDS Working Paper 170). Sussex: Institute of Development Studies.

Crenshawe, K. (1993). Mapping the Margins: Intersectionality, Identity Politics and Violence against Women of Colour. Stanford Law Review, 43(124), 60. 
Dagnino, E. (2007). Citizenship: a perverse confluence. Development in Practice, 17(4-5), 549-556. doi: 10.1080/09614520701469534

de Haan, A. (2007). Labelling 'Works': The Language and Politics of Caste and Tribe in India. In J. a. E. Moncrieffe, Rosalind (Ed.), The power of labelling : how people are categorized and why it matters. London: Earthscan.

Elson, D., \& Cagatay, N. (2000). The Social Content of Macroeconomic Policies. World Development, 28(7), 1347-1364. doi: http://dx.doi.org/10.1016/S0305$\underline{750 X(00) 00021-8}$

Eyben, R. (2007). Labelling people for aid. In M. a. Eyben (Ed.), The Power of Labelling: How People are Categorized and Why it Matters: Earthscan UK and USA.

Fraser, N. (2003). Social Justice in the Age of Identity Politics: Redistribution, Recognition and Participation. In N. a. A. H. Fraser (Ed.), Redistribution or Recognition? A Political Philosophical Exchange (pp. 7-109). London \& New York: Verso.

Frediani, C. B. a. A. A. (2012). Processes for Just Products: The Capability Space of Participtory Design. In O. I. a. J. v. d. Hoven (Ed.), The Capability Approach, Technology and Design (pp. 203 - 222). UK: Springer.

Karanja, I. (2010). An enumeration and mapping of informal settlements in Kisumu, Kenya, implemented by their inhabitants. Environment and Urbanization, 22(1), 217-239. doi: $10.1177 / 0956247809362642$

Levy, C. (2000). Addressing men and masculinities in GAD. IDS Bulletin, 31(2).

Levy, C. (2013). Travel choice reframed: 'deep distribution' and gender in urban transport. Environment and Urbanization, 25(1), 47-63. doi: 10.1177/0956247813477810

Moncrieffe, J., \& Eyben, R. (2007). The power of labelling : how people are categorized and why it matters. London: Earthscan. 
Moser, C. (1993). Gender, Planning and Development: Theory, Practice and Training. London and New York: Routledge.

Mouffe, C. (2002). Politics and Passions: The Stakes of Democracy. In C. f. t. S. o. D. University of Westminster (Ed.), (pp. 1-16). London.

Mukhopadhyay, M. (2004). Mainstreaming Gender or 'Streaming' Gender Away: Feminists Marooned in the Development Business. IDS Bulletin, 35(4), 95-103. doi: 10.1111/j.1759-5436.2004.tb00161.x

Muna, W. K., Stanton, A., \& Mwau, D. M. (2014). Deconstructing intergenerational politics between 'Young Turks' and 'Old Guards' in Africa: an exploration of the perceptions on leadership and governance in Kenya. Journal of Youth Studies, 17(10), 1378-1394. doi: 10.1080/13676261.2014.918248

Phillips, A. (1994). Dealing With Difference: A Politics of Ideas or a Politics of Presence? . Constellations, 1(1), 74-91.

Phillips, A. (1997). From inequality to difference: A severe case of displacement? New Left Review(224), 143-153.

Purdie-Vaughns, V., \& Eibach, R. (2008). Intersectional Invisibility: The Distinctive Advantages and Disadvantages of Multiple Subordinate-Group Identities. Sex Roles, 59(5-6), 377-391. doi: 10.1007/s11199-008-9424-4

Rigon, A. (2014). Building Local Governance: Participation and Elite Capture in Slumupgrading in Kenya. Development and Change, 45(2), 257-283. doi: 10.1111/dech.12078

Sigona, N. (2005). Locating 'The Gypsy Problem'. The Roma in Italy: Stereotyping, Labelling and 'Nomad Camps'. Journal of Ethnic and Migration Studies, 31(4), 741756. doi: 10.1080/13691830500109969 
STDP, S. T. D. P. (No date). Guidelines for Upgrading of Informal Settlements Based on Minimum Intervention Approach (MINA) Kenya.

Sweetman, C. (2001). Men's Involvement in Gender and Development Policy and Practice: Beyond Rhetoric (Vol. Oxfam Working Papers Series). Oxford: Oxfam.

van Biezen, I., \& Rashkova, E. R. (2013). INTRODUCTION: GENDER POLITICS AND PARTY REGULATION. QUOTAS AND BEYOND. Representation, 49(4), 393400. doi: $10.1080 / 00344893.2013 .850319$

Von Lieres, B. , \& Piper, L. (2014). Mediated citizenship : the informal politics of speaking for citizens in the global south: Palgrave Macmillan.

Walker, J. (2013). Time poverty, gender and well-being: lessons from the Kyrgyz Swiss Swedish Health Programme. Development in Practice, 23(1), 57-68. doi: $10.1080 / 09614524.2013 .751357$

Walker, J., Frediani, A. A., \& Trani, J. F. (2012). Gender, difference and urban change: implications for the promotion of well-being? Environment and Urbanization, 25(1), 111-124. doi: 10.1177/0956247812468996

White, S. C. (2002). Being, becoming and relationship: conceptual challenges of a child rights approach in development. Journal of International Development, 14(8), 10951104. doi: $10.1002 / \mathrm{jid} .950$

Yuval-Davis, N. (1999). What is 'Transversal Politics'? Soundings: A Journal of Politics and Culture(12), 94 - 99. 